\title{
Peningkatan Kompetensi Auto CAD Bagi Siswa SMK Ma'arif NU Talang Kabupaten Tegal
}

\author{
Amin Nur Akhmadi*1, M. Taufik Qurohman ${ }^{2}$, Syarifudin $^{3}$ \\ 1,2,3 Program Studi Teknik Mesin, Politeknik Harapan Bersama \\ e-mail: 1aminnurakhmadi@gmail.com, 2taufikqurohman@gmail.com, \\ ${ }^{3}$ masudinsyarif@gmail.com
}

\begin{abstract}
Abstrak
Pembelajaran di sekolah menggunakan media dapat membantu keberhasilan proses belajar mengajar. Pembelajaran yang dilaksanakan di sekolah tentu tidaklah hanya sekedar mempelajari tentang teori saja. Pada pengabdian ini penggunaan media dengan bersasis AutoCad diharapkan dapat meningkatkan hasil belajar siswa. Mengingat selain mempelajari teori siswa juga belajar untuk menerapkan apa yang telah mereka pelajari didalam kegiatan praktek, misalnya dalam proses penggambaran Di SMK Ma'arif Nu Talang Kabupaten Tegal secara factual masih kurangnya siswa yang memanfaatkan AutoCAd sebagai alat bantu penggambaran dikarenakan masih seringnya penggambaran secara manual, Pengabdian ini bertujuan untuk 1) Mengetahui gambaran pemanfaatan AutoCad pada standar kompetensi menggambar konstruksi baut;2)Mengetahui hasil belajar siswa pada standar kompetensi menggambar konstruksi baut;3) mengetahui seberapa besar pengaruh pemanfaatan AutoCad terhadap hasil belajar siswa pada standar kompetensi menggambar konstruksi baut. Dalam Pengabdian ini menggunakan pendekatan metode presentasi dan diskusi. Sampel penganbdian dalam pengabdian ini berjumlah 10 siswa diambil dari kelas 12 pilihan. Kesimpulan pengabdian ini adalah pelatihan Auto Cad bagi siswa SMK Ma'arif Nu Talang dalam penyelesaian tuga pada standar kompetensi menggambar konstruksi baut.
\end{abstract}

Kata kunci-Pelatihan Auto Cad, Belajar Siswa SMK

\section{PENDAHULUAN}

SMK Ma'arif Nu Talang Kecamatan Talang sekolah ini terletak di Desa Talang Kabupaten Tegal dimana jumlah Siswa-siswinya mencapai 765 jiwa, dan kebanyakan masyarakatnya berprofesi sebagai wirausaha, seperti halnya UKM [1].

Talang merupakan salah satu desa yang berada di kecamatan talang, kabupaten tegal, provinsi jawa tengah, indonesia. letak desa talang berada di jalan utama tegal purwokerto. terbagi dalam $2 \mathrm{rw}$ dan $11 \mathrm{rt}$. sebelah barat jalan utama adalah rw 1 meliputi rt 1 - 6, sedangkan sebelah timur jalan raya adalah rw. 2 meliputi rt. 7-11. desa talang berbatasan sebelah utara dengan desa pagongan, kec. dukuhturi; sebelah selatan dengan desa kajen, kec. talang. untuk sebelah barat berbatasan dengan desa kebasen dan desa tegalwangi, kemudian sebelah timur berbatasan dengan desa pesayangan.[2]

Tujuan Pengabdian ini adalah memberikan bekal ketrampilan/kompetensi menggambar mesin sekolah SMK Ma'arif $\mathrm{Nu}$ Talang sebagai modal pengembangan pembelajaran disekolah bagi siswa dan siswi bekal memasuki lapangan kerja atau berwira usaha bagi siswa. Selain itu juga untuk membantu pembelajaran produktif SMK Ma'arif $\mathrm{Nu}$ Talang yang kekurangan dan fasilitas praktikum.

Metode yang digunakan untuk memecahkan permasalahan yang telah dirumuskan, maka diperlukan metode yang harus diikuti agar dapat dilakukan penyelesaiannya dengan baik. Berikut ini metode pemecahannya yaitu; 1) Survei di SMK $\mathrm{Ma}$ arif $\mathrm{Nu}$ Talang untuk mendapatkan data yang sesuai kebutuhan. 2) merumuskan materi 
pelatihan, 3) membuat jadwal pelaksanaan pelatihan berkaitan dengan waktu, 4) menyusun anggaran untuk pengadaan bahan praktik dalam pelatihan, 5) menyusun instruktur yang akan memberikan pelatihan. 6) membuat rancangan evaluasi kegiatan. 7) melaksanakan kegiatan pelatihan gambar mesin yang diikuti siswa dan siswi [3]

Hasil pelaksanaan Pengabdian Masyarakat sebagai berikut; 1) pelatihan yang cocok bagi siswa SMK Ma'arif Nu Talang adalah pelatihan gambar mesin AutoCAD. 2) Ketrampilan gambar mesin yang dapat membekali siswa SMK Ma'arif Nu Talang memasuki dunia kerja adalah; a) menggambar mesin dengan Autocad yang benar. b) membuat Workspaces untuk mengganti display pada AutoCAD 3). Materi pelatihan adalah teknik pelatihan menggambar mesin Autocad, Menggambar dasar autocad, menentukan 3D View terdapat 3 garis sumbu $(X, Y, Z)$ dan pada 2D View hanya 2 garis sumbu $(X, Y)$. Sumbu Z pada 2D View, menggunakan User Coordinat System.[4]

Materi praktik diarahkan pada proses menggambar dasar 2D, Tanggapan dari guru dan siswa SMK Ma'arif Nu Talang dengan adanya pelatihan ini mereka senang mendapatkan ilmu menggambar mesin karena selama ini belum pernah karena kurang fasilitas dan mengharapkan ada pelatihan serupa dan secara rutin..

\section{METODE}

\subsection{Sasaran Kegiatan PKM}

Sasaran pada kegiatan pengabdian masyarakat ini yang dijadikan sebagai mitra adalah siswa SMK Ma'arif $\mathrm{Nu}$ Talang kelas 11 dari jurusan otomotif sebanyak 10 orang peserta kegiatan. Dalam pelaksanaanya kegiatan yang telah dilaksanakan terdapat beberapa faktor pendukung dan pendorong sehingga kegiatan dapat berjalan dengan lancar, diantaranya: (1) Media pelengkapan presentasi untuk pelatihan sangat memadai, sumber listrik, LCD dan pendukung lainnya juga sudah dipersiapkan dengan baik; (2) Peserta kegiatan dalam hal ini para siswa SMK Ma'arif Nu Talang sangat antusias mengikuti kegiatan ini; (3) Dukungan pihak sekolah yang memberikan motivasi tersendiri dalam menyukseskan acara pelatihan.

\subsection{Metode Kegiatan}

Metode kegiatan yang digunakan untuk mencapai tujuan dari kegiatan pengabdian masyarakat ini adalah dengan metode ceramah, diskusi dan praktek dimana pada bagian ini para peserta diberikan kesempatan untuk membuat dan mempraktekkan apa yang telah disampaikan mulai dari pembuatan desain gambar pada Auto CAD sampai dengan pembuatan tugas gambar baut.

\subsection{Tahapan Kegiatan PKM}

\section{3.1 Persiapan}

Sebelum kegiatan dilaksanakan maka dilakukan persiapan-persiapan sebagai berikut: (1) Melakukan survei terhadap kebutuhan dan permasalahan yang dihadapai oleh para siswa SMK Ma'arif Nu Talang Kabupaten Tegal dalam proses belajar mengajar; (2) Melakukan studi pustaka mengenai penerapan menggambar Auto Cad sebagai alat bantu dalam proses belajar mengajar di kelas. (3) Melakukan persiapan perlengkapan serta peralatan sesuai kebutuhan yang diperlukan; (4) Menentukan waktu pelaksanaan dan lamanya kegiatan pengabdian bersama- sama tim pelaksana; (5) Menentukan dan mempersiapkan materi yang akan disampaikan dalam kegiatan pengabdian masyarakat.

\section{3.2 Pelaksanaan Kegiatan}

Pelaksanaan kegiatan pengabdian berlangsung pada tanggal 19-22 September 2016. Pelaksanaan kegiatan dilaksanaakan pada pukul 13.00 s.d selesai WIB dengan tempat di Lab. 
komputer SMK Ma'arif $\mathrm{Nu}$ Talang Kabupaten Tegal. Materi yang disampaikan terkait dengan proses menggambar AutoCad yang digunakan untuk media pembelajaran proses belajar mengajar diantaranya adalah mengenai menggambar AutoCad dalam Membantu Kegiatan Belajar Mengajar, Pembuatan Desain dan Pengaturan dalam Fungsi AutoCad, dan Penggunaan Gambar 3D Bagi Siswa

\section{3.3 Evaluasi Kegiatan}

Untuk mencapai target tujuan dari pelatihan ini, maka pada evaluasi kegiatan peserta pelatihan diberikan tugas untuk membuat gambar baut sesuai dengan dimensinya masing-masing. Hasil akhir capaian kegiatan adalah sebuah gambar baud 2D yang didalamnya terdapat beberapa bentuk gambar bagian yang telah dibuat untuk dapat diterapkan pada sat proses pembelajaran gambar teknik di kelas.

\section{HASIL DAN PEMBAHASAN}

\subsection{Kegiatan Pelatihan}

Sebagai upaya dalam peningkatan kemampuan siswa dalam peningkatan mata pelajaran gambar teknik AutoCad yaitu pada pembuatan pembelajaran dalam bentuk Auto $\mathrm{Cad}$, pelatihan dilakukan bagi siswa. Peserta kegiatan diberikan berbagai macam materi, diantaranya adalah sebagai berikut:

- Menggambar dasar AutoCad

- Pengenalan Fungsi Tombol Keyboard pada AutoCad

- Pengenalan Toolbar AutoCad

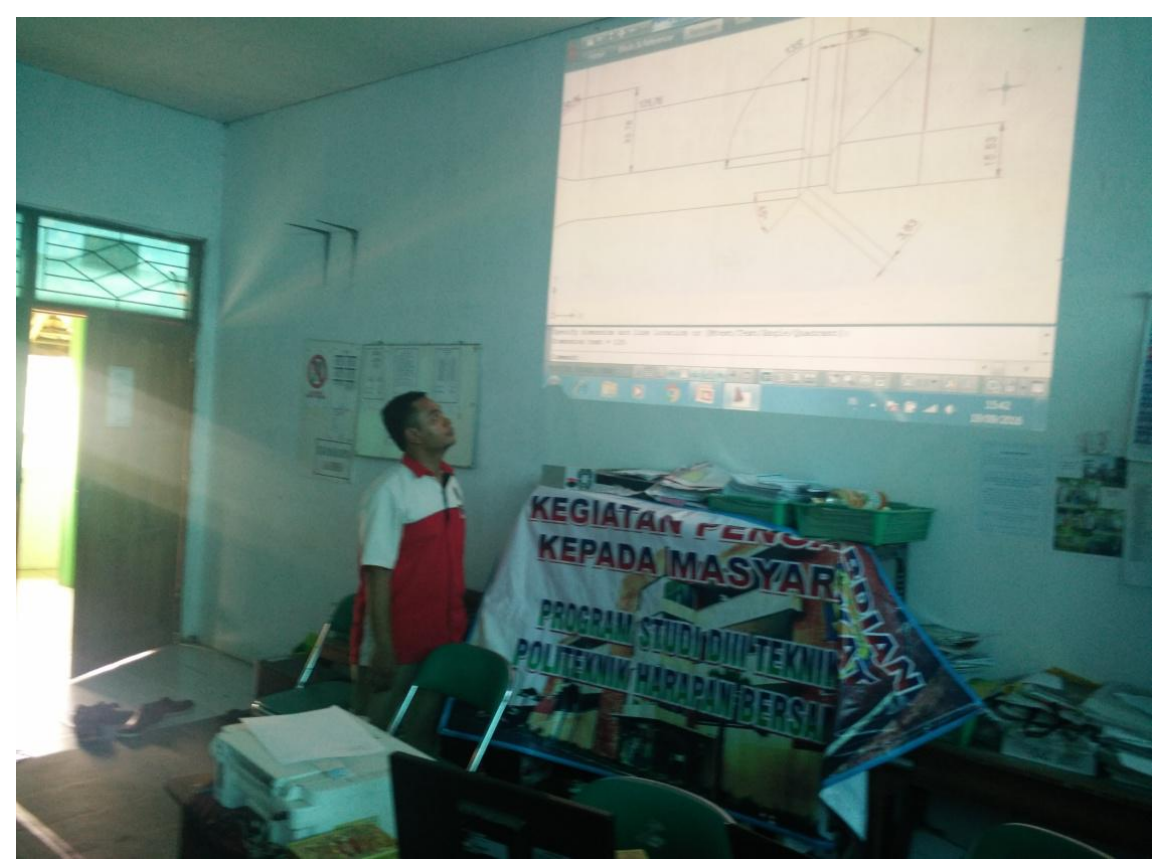

Gambar.1. Kegiatan Pengabdian di SMK Ma'arif Nu Talang Kabupaten Tegal 


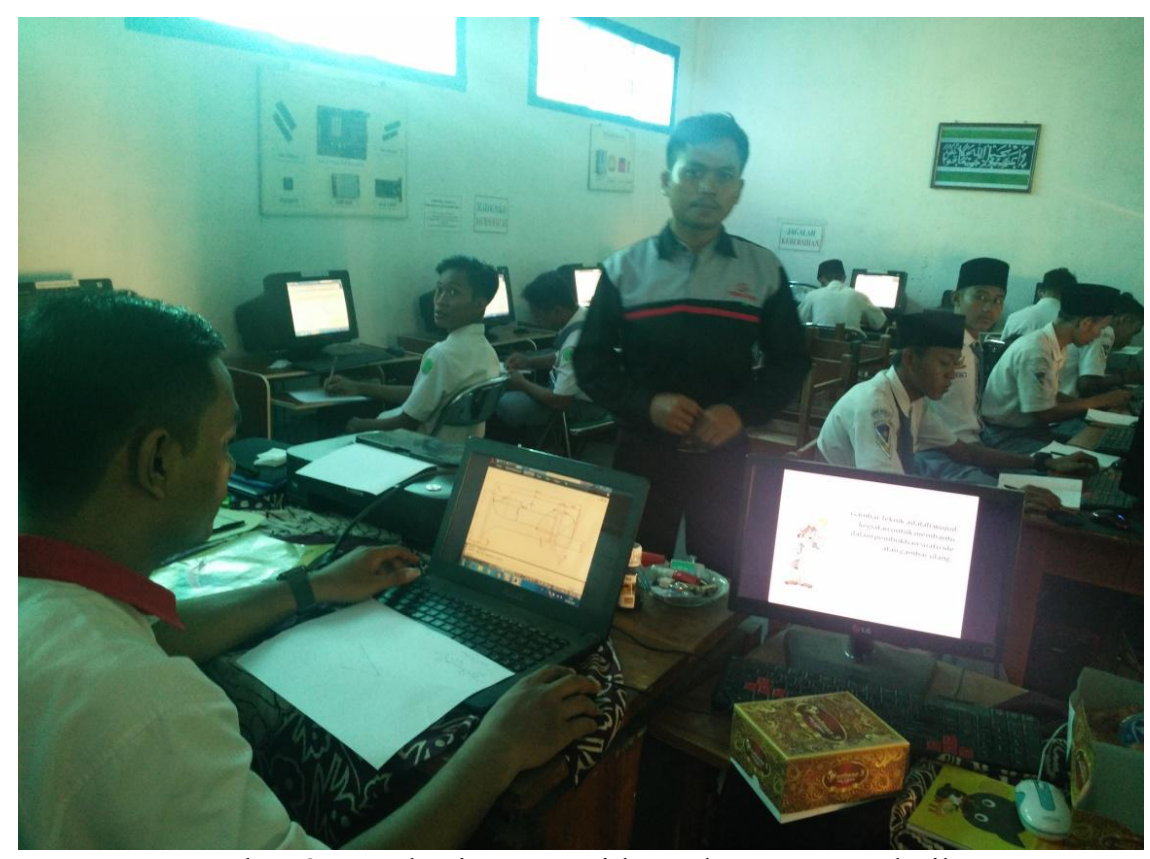

Gambar 2. Pemberian materi kepada peserta pelatihan

Pada Gambar 1 dan Gambar 2 memperlihatkan proses kegiatan pelatihan AutoCad yang diikuti oleh para peserta kegiatan. Pada kegiatan ini proses pemberian materi dilakukan oleh tim pelaksana PKM yang terdiri dari Dosen dan mahasiswa sebagai tim pembantu teknik pelaksanakan PKM.

\subsection{Pendampingan Program}

Dalam pelaksanaan kegiatan pelatihan AutoCad tersebut untuk memperoleh hasil luaran yang optimal maka dilakukan pendampingan baik itu pada saat proses pelaksanaan maupun pasca pelaksanaan pelatihan. Pada pelatihan ini Mahasiswa dilibatkan sebagai tim pendamping yang mendampingi peserta pelatihan agar setiap peserta dapat dengan mudah baik dalam proses pembuatan gambar dasar AutoCad maupun Toolbar AutoCad pada media pembelajaran tersebut. [5]

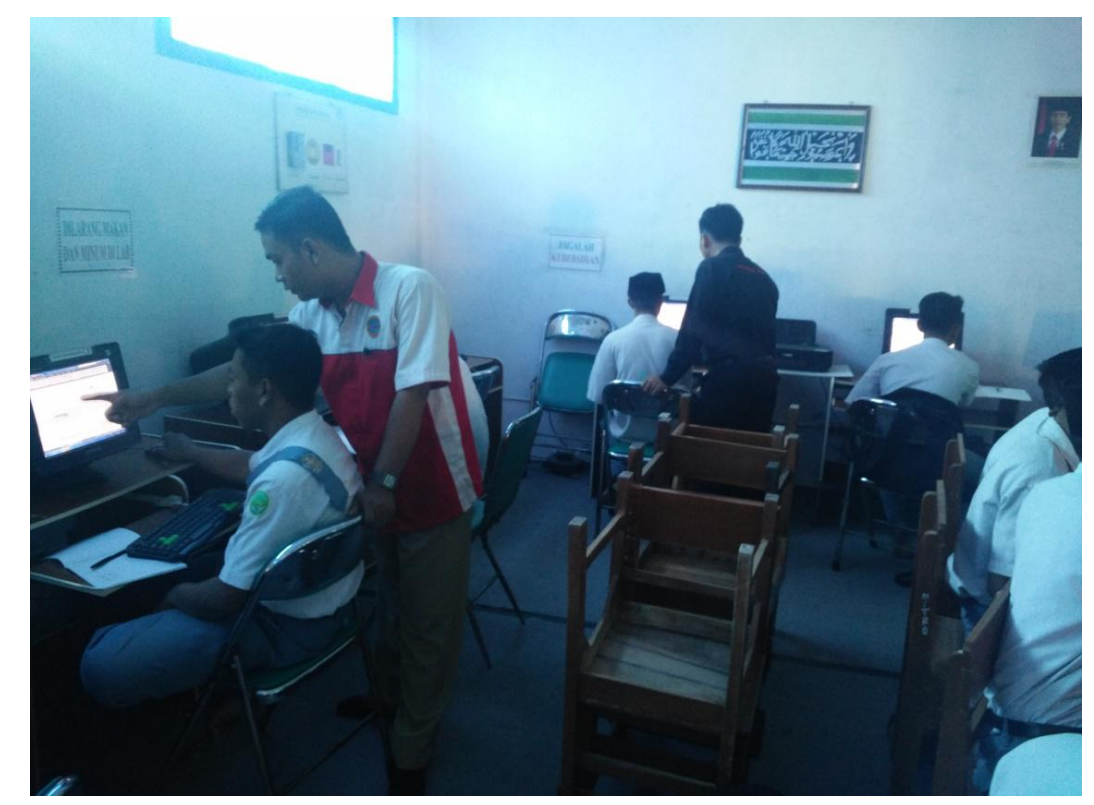

Gambar 3. Proses Pendampingan peserta kegiatan 


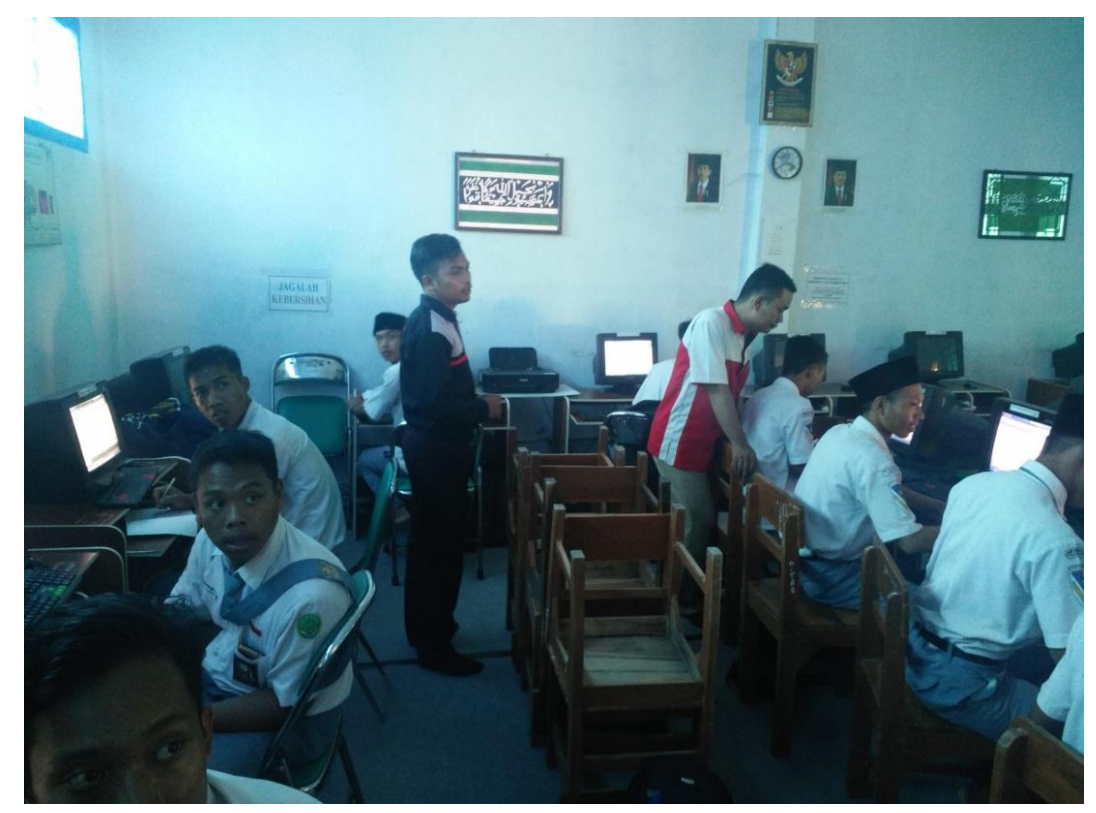

Gambar 4. Proses Pendampingan oleh mahasiswa

Pada Gambar 4 dan Gambar 5 memperlihatkan kegiatan pendampingan pada saat proses pelatihan, dimana pendampingan dilakukan oleh tim pelaksanaan PKM dan Mahasiswa. Pada proses pendampingan ini peserta kegiatan diarahkan dan dibimbing langsung face-to face sehingga harapannya dapat lebih optimal dalam proses

\subsection{Capaian Kegiatan}

Kegiatan pengabdian pada masyarakat ini menghasilkan beberapa kegiatan yang dihasilkan diantaranya sebagai berikut: (1) Pemberian materi pelatihan yang diberikan kepada para siswa SMK Ma'arif $\mathrm{Nu}$ Talang Kabupaten Tegal diterima dengan respon yang positif oleh para peserta kegiatan, disamping itu penggunaan media AutoCad yang dianggap masih baru oleh para peserta memberikan daya tarik tertentu bagi para peserta sehingga banyak para peserta pelatihan yang tertarik; (2) Berdasarkan hasil praktek terhadap penggunaan gambar Teknik AutoCad ini, telah dihasilkan beberapa konsep gambar baru dari AutoCad yang dibuat sehingga setelah kegiatan ini selesai para peserta kegiatan dapat langsung mempraktekannya; (3) Adanya ketertarikan dan keinginan dari kepala Sekolah SMK Ma'arif $\mathrm{Nu}$ Talang Kabupaten Tegal untuk dapat mengimplementasikan hasil dari program pelatihan yang telah dilaksanakan. [7] 


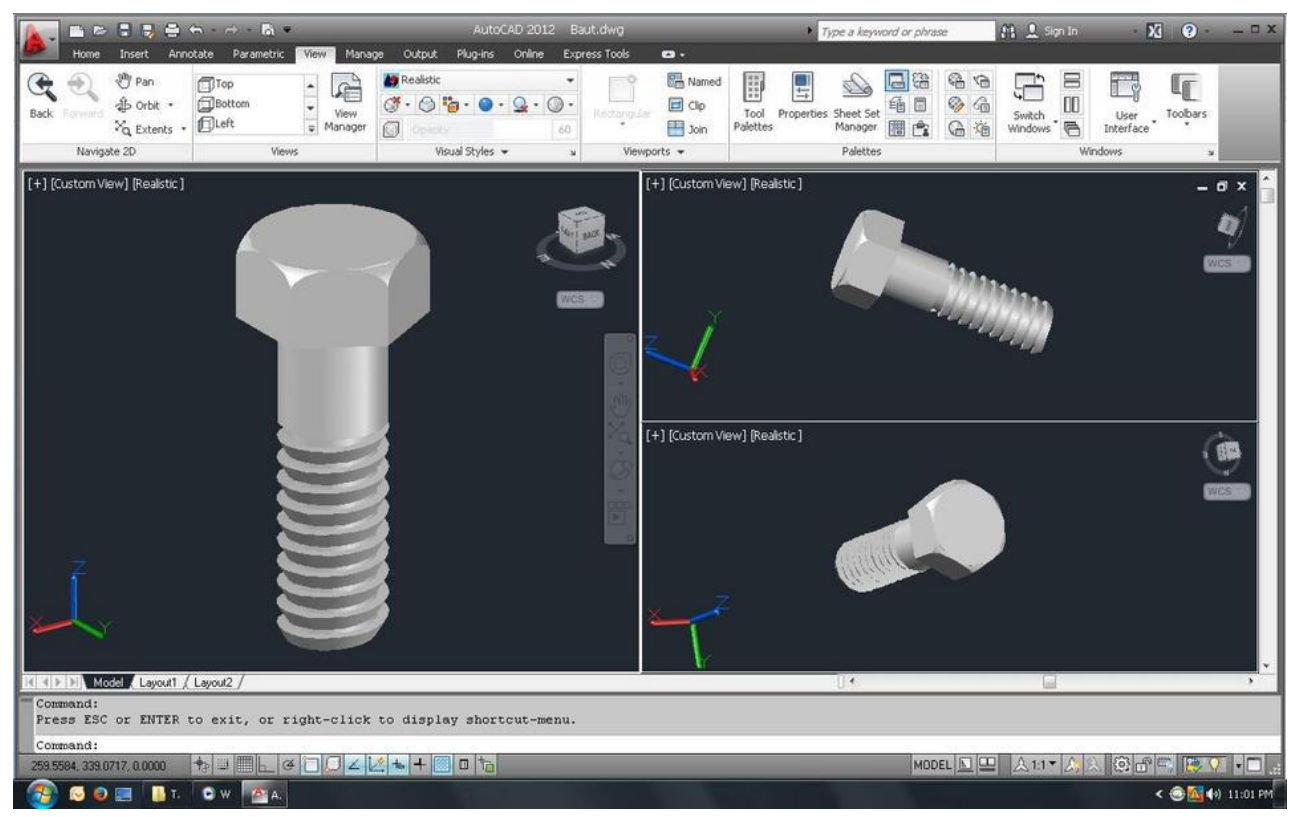

Gambar 5. Modelling gambar baut pada AutoCad [6]

\section{KESIMPULAN}

Pemanfaatan teknologi dalam menggambar mesin dalam bentuk gambar teknik aplikasi AutoCad sebagai sarananya sangat membantu dalam proses kegiatan belajar di SMK Ma'arif Nu Talang Kabupaten Tegal. Pembelajaran tutorial di dalam kelas dapat disinkronkan dengan bantuan mahasiswa untuk membantu menambahkan materi, membuat tugas menggambar, hingga ujian praktek menggambar. SMK Ma'arif Nu Talang Kabupaten Tegal memiliki metode pembelajaran berbasis Gambar Teknik AutoCad yang dapat dijadikan sebagai salah satu alternatif pembelajaran gambar Teknik.

\section{SARAN}

Mengingat besarnya manfaat kegiatan pengabdian pada masyarakat ini, maka saran yang dapat dipertimbangkan diantaranya:

- Adanya pelatihan yang berkelanjutan bagi siswa SMK Ma'arif $\mathrm{Nu}$ Talang kabupaten Tegal sehingga dapat memperdalam kembali pengetahuan mengenai gambar teknik AutoCad dan penerapannya.

- Perlu adanya evaluasi terhadap penggunaan Aplikasi AutoCad yang sudah diberikan sehingga kita dapat mengukur sejauh mana keberhasilan dari pelatihan yang telah diberikan kepada para peserta kegiatan.

\section{UCAPAN TERIMA KASIH}

Terima kasih kepada Pusat Penelitian dan Pengabdian Masyarakat (P3M) Politeknik Harapan Bersama Tegal yang telah membiayai kegiatan PKM yang telah dilaksanakan ini pada tahun anggaran 2016. 


\section{DAFTAR PUSTAKA}

[1] http://dayintapinasthika.blogspot.co.id Ekonomi Skala Kecil/Menengah \& Koperasi.Html

[2] https://id.wikipedia.org/wiki/Talang,_Tegal

[3] Anita Lie (Herdian, S.Pd). Model dan Prinsip Model Belajar (http://herdy07.wordpress.com/2009/04/29)

[4] Adi Sulistio,Pengenalan Autocad 2D dan 3D Untuk Industri Manufaktur, Andi, jogjakarta.

[5] Muhammad Faiq Dzaki. Langkah-langkah Model Pendampingan Program ((http:/pbsindonesia.fkipuninus.org/media.php?module=detailmateri\&id=97)

[6] Heri Zezen I, Sudarna, Supardi, (2001), Risalah Praktikum Perancangan Sistem Konsep Gambar, Teknik Industri, Universitas Komputer Indonesia, Bandung.

[7] Suparno Sastra M, Menjadi Desainer professional Dengan Autocad 2006 (2D dan 3D), Andi, Jogjakarta. 